\title{
Towards an Understanding of Racial Differences in Post-stroke Disability
}

\author{
Lesli E. Skolarus $^{1}$ • James F. Burke ${ }^{1}$
}

Published online: 26 June 2015

(C) Springer International Publishing AG 2015

\begin{abstract}
Due to the aging of the baby boomer generation, the number of stroke survivors is expected to increase from seven million to over ten million in 2030. Stroke survivorship will be particularly important for African-Americans who have a higher incidence of strokes compared to nonHispanics whites and greater post-stroke disability. Current evidence suggests that the most prominent racial differences in post-stroke disability emerge in the post-stroke period. Further work, with a focus on modifiable factors, is needed to understand which factors in the post-stroke period lead to racial differences in post-stroke disability.
\end{abstract}

Keywords Stroke survivors · Disability $\cdot$ Race

\section{Introduction}

Each year, about 800,000 Americans have a stroke, of which $75 \%$ occur among those 65 and older [1, 2]. Currently, there are seven million US stroke survivors, and this number is projected to increase to ten million by 2030 given the aging of the population $[3,4]$. Because most people survive their stroke, disability is the greatest challenge facing survivors and their families: About a third of stroke survivors have a severe/ moderate disability and another third have a mild disability

This article is part of the Topical Collection on Cardiovascular Disease

Lesli E. Skolarus

lerusche@umich.edu

James F. Burke

jamesbur@med.umich.edu

1 Stroke Program, Department of Neurology, University of Michigan, 1500 East Medical Center Drive SPC\#5855, Ann Arbor, MI 48109-5855, USA
$[5,6]$. Not surprisingly, stroke is a leading cause of disability in the USA [2].

Non-Hispanic Black/African-American (AA) adults have a higher stroke incidence than non-Hispanic white (NHW) adults (AA-NHW age sex-adjusted IRR for all strokes was 1.51 (95\% CI, 1.26-1.81)), and racial disparities in stroke incidence have worsened over time $[7 \bullet \bullet, 8 \bullet]$. Racial difference in stroke incidence is most pronounced among the working age population [9]. Given that case fatality does not markedly differ by race [10], AAs thus have the highest stroke prevalence of any US racial/ethnic group and the prevalence is expected to increase by over $25 \%$ by $2030[3,11]$. The purpose of this paper is to provide an update on existing knowledge regarding the existence of racial differences in poststroke disability. We propose a conceptual framework of racial differences in post-stroke disability spanning the pre-stroke to the community living period and discuss relevant factors that may contribute to racial differences in disability in each period.

\section{Post-stroke Disability Among African-Americans}

Studies of post-stroke disability have generally found a trend towards more severe disability among AAs, but results have varied, depending on the specific population and outcomes studied. One recent study of community-dwelling stroke survivors with a caregiver found that AA stroke survivors had more severe disability (greater activity limitations as measured by the Barthel Index and portions of the Stroke Impact Scale) than NHWs 1 year after their stroke [12]. Another study of patients who underwent inpatient rehabilitation showed that AAs had lower functional independence measure scores (more limitations in activities) at admission and at discharge from inpatient rehabilitation than NHWs [13]. Conversely, 
two population-based studies found no differences in disability by race. The Greater Cincinnati/Northern Kentucky Stroke Study found no racial differences in post-stroke disability measured by the modified Rankin Scale at 3 months and 4 years post-stroke [14]. The Northern Manhattan stroke study also found no racial difference in post-stroke disability measured by the Barthel Index at 6 months and among long-term stroke survivors [15]. There are various limitations to these studies including lack of national representativeness, use of dichotomous outcome measures limiting the power to detect small difference [15], reliance on selected populations $[12,13]$, and considerable loss to follow-up [12, 14].

A recent study using nationally representative crosssectional data from the National Health and Aging Trends Study (NHATS) found substantially more severe disability in elderly AA adults than in NHW adults with self-reported stroke [16•]. NHATS is an annual study of over 8000 Medicare beneficiaries ages 65 and older who undergo face-to-face interviews in their place of residence. NHATS oversamples AAs and people in older age groups. Disability was defined as receiving assistance with a given task among each of the seven self-care and mobility activities (eating, bathing/ showering, toileting, dressing, getting out of bed, getting around within one's home, and leaving one's home) and five household activities (doing own laundry, grocery shopping, making hot meals, handling bills/banking, and administering medications). AA stroke survivors were found to have, on average, $25 \%$ more limitations in self-care, mobility, and household activities than NHWs. These racial differences persisted after accounting for age, sex, comorbidities, education, and marital status.

\section{The Emergence of Racial Differences in Post-stroke Disability}

Understanding when racial differences in post-stroke disability emerge and what is driving them is essential to eliminating racial disparities in stroke survivors. Racial differences in post-stroke disability may reflect pre-stroke racial differences in disability or may arise in the acute stroke, early recovery, or community living periods. Different factors are likely to drive disability during each of these periods (Fig. 1).

\section{Pre-stroke}

Medical comorbidities and cognitive function may play a role in post-stroke disability as pre-stroke disability is a wellknown predictor of post-stroke disability [17]. A study of older Americans participating in the Health and Retirement Study (HRS) found that pre-stroke racial differences in instrumental activities of daily living (IADL) narrowed at the time of the stroke [18]. In contrast, a recent analysis using the Panel
Study of Income Dynamics (PSID), a nationally representative US panel survey of families and their descendants, found no pre-stroke racial differences in activities of daily living (ADL) limitations [19]. Racial differences arose in the incident stroke wave (between 0 and 2 years from incident stroke) when AAs had more ADL limitations than NHWs (2.2 vs. 1.5, $p=0.048$ ). This racial difference persisted after accounting for age, sex, and comorbidities. This study also showed small prestroke racial differences in IADL limitations that widened at the time of the stroke and persisted. Thus, differences in prestroke disability may be less important for racial differences in post-stroke disability than previously suggested.

\section{Acute Stroke}

The acute period has been studied extensively and has not offered obvious explanations for racial differences in poststroke disability. Biological differences in stroke do not appear to account for racial differences in post-stroke disability. AA stroke patients have fewer cardioembolic, a severe type of stroke, than NHWs $[20,21]$. Stroke severity is the most important predictor of post-stroke disability [22] and data from population-based studies [23-25], a nationwide registry [26] and the VA [27] all find that there is no difference in stroke severity by race. Similarly, AA stroke patients receive comparable quality of acute stroke care compared to NHWs. To the extent that any differences in quality of care do exist, they are too small to account for the magnitude of described racial differences in disability [28].

\section{Post-stroke: Early Recovery Period}

The post-stroke period is comprised of two distinct time intervals. In the first 6-12 months after a stroke, we term this as the early recovery period given that stroke survivors will improve during this time. After this period, stroke survivors' recovery has often plateaued and they are re-integrated into their community. We term this period as the community living period. Differences in the patterns of longitudinal post-stroke disability likely differ by race, but are poorly characterized. AAs have greater overall mortality from strokes than NHWs mostly due to the increased stroke incidence among AAs [7••]. However, AAs have equal or lower case fatality than NHWs largely due to their younger age at the time of stroke [10]. Thus, there are two primary, non-exclusive, hypotheses related to the development of racial differences in post-stroke disability, as depicted in Fig. 2. First, compared to NHWs (black line), AA stroke survivors may have less improvement in the early recovery period (long-dashed dark grey line), leading to lower community living baseline function. Second, there may be no racial differences in post-stroke disability after the early recovery period, but then Black stroke survivors may decline more rapidly (short-dashed light grey line) than Whites during the 


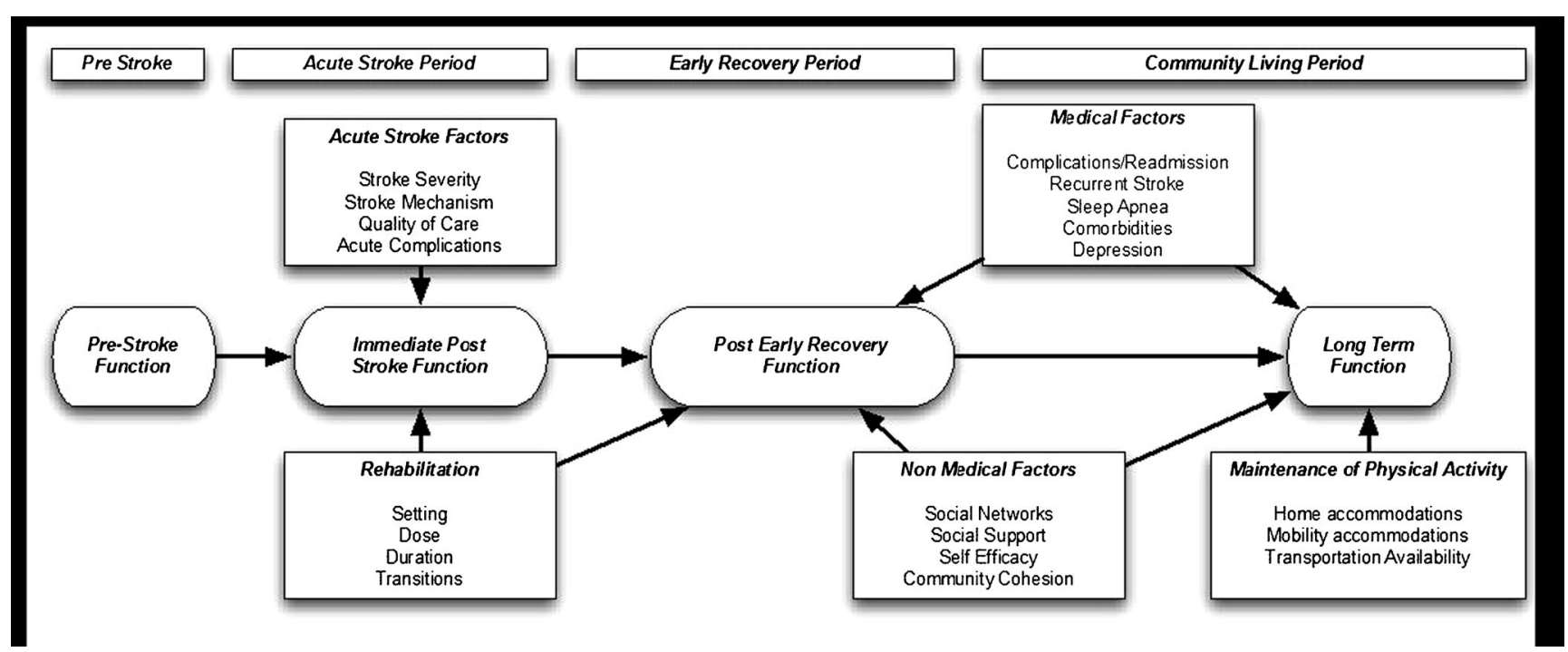

Fig. 1 Conceptual model of the stroke survivor

community living period. Alternatively, given their younger age of stroke onset [9] and the equal or lower case fatality [10], it may be that AAs live longer after their stroke and although the slope of the decline in function is the same, the duration is longer for AAs, leading to the observed differences in disability in cross-sectional studies. Given that different factors would likely underlie these temporal patterns, a better understanding of racial differences in longitudinal outcomes after stroke may inform both the causes of racial differences and offer guidance for how to eliminate these differences.

The early recovery period is important for understanding long-term outcomes after stroke as one unique aspect of disability caused by stroke is the tremendous potential for recovery. Unlike other neurologic diseases, such as dementia, which are characterized by a progressive decline in function, stroke survivors are often at their maximal disability during their hospital stay and then improve during the following 612 months [29]. Thus, racial differences in the early recovery period including post-acute care, medical and non-medical (e.g., social, behavioral, and personality) factors may be important modifiable risk factors associated with race differences in post-stroke disability.

Post-acute care, in the form of rehabilitation, reduces poststroke disability [30-32]. Rehabilitation occurs in a range of settings, from home health agency therapy in private residences, to outpatient rehabilitation, to institutions which

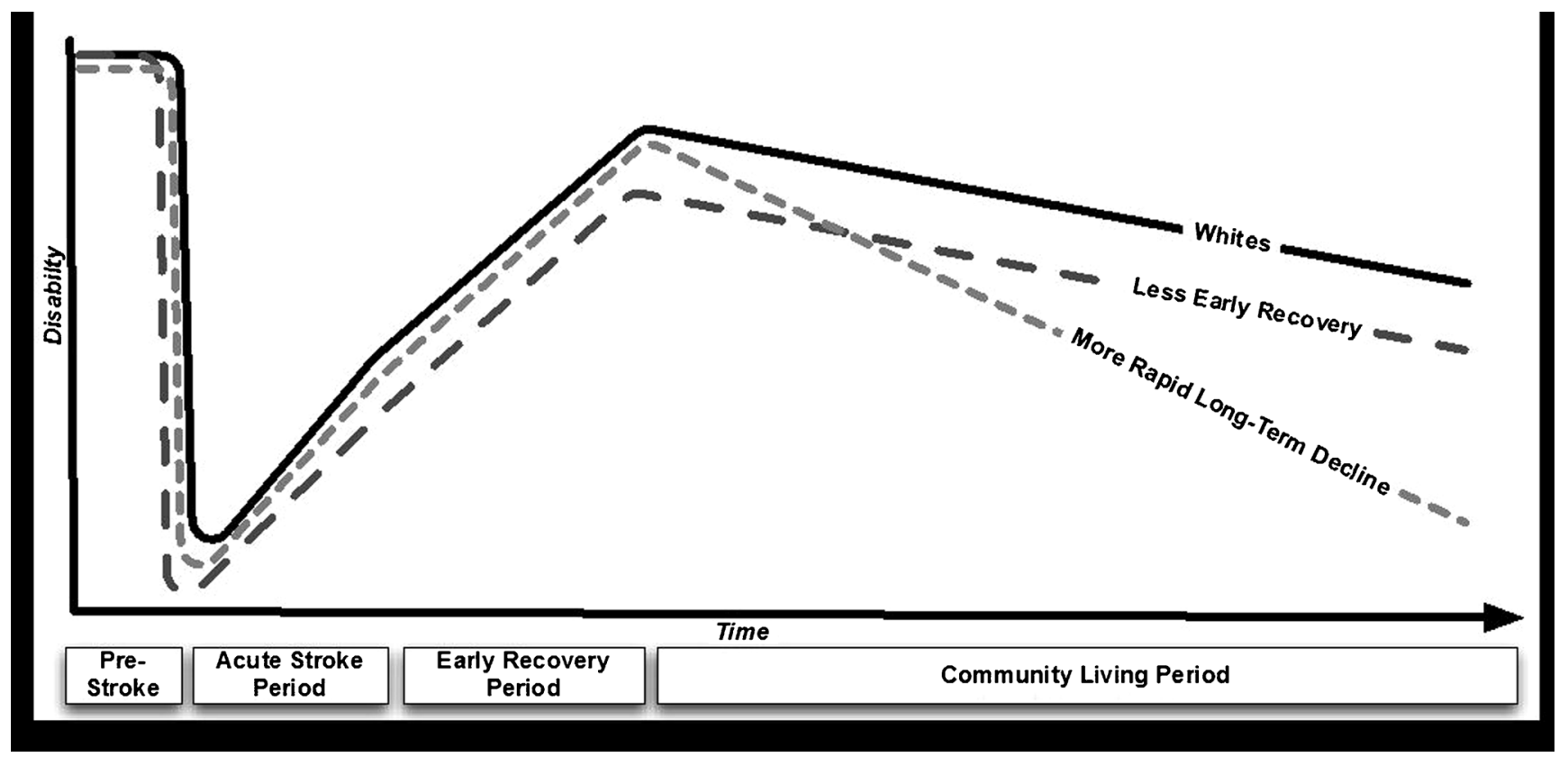

Fig. 2 Potential explanations for when racial differences in long-term outcomes after stroke arise 
include both inpatient rehabilitation facilities (IRFs) and skilled nursing facilities (SNFs). Among stroke survivors with Medicare, about $20 \%$ are discharged to an IRF, $25 \%$ are discharged to a SNF, and $12 \%$ receive home health [33]. The intensity of rehabilitation varies from at least $3 \mathrm{~h}$ of rehabilitation per day in an IRF to variable amounts of less frequent rehabilitation in a SNF (less than $1 \mathrm{~h}$ a day) to rehabilitation 1-2 times per week via home health or outpatient physical therapy $[34,35]$. Higher intensity rehabilitation leads to better outcomes in stroke patients. Randomized controlled trials have shown that more intense rehabilitation settings [36], higher intensity rehabilitation in comparable settings [37], and the use of outpatient and home therapy [38] reduce disability compared to less intense rehabilitation. High-quality observational data suggests that admission of stroke survivors to an IRF rather than a SNF leads to decreased disability, institutionalization, and mortality [39-42]. Whether rehabilitation intensity varies by race nationally is unknown. Such variation may well exist as regional data suggests that $\mathrm{AA}$ stroke survivors who are discharged to institutional rehabilitation are more likely to be discharged to less intense rehabilitation settings (SNF vs. IRF) compared to NHWs [43]. Given the efficacy of higher intensity rehabilitation and that disabled acute stroke survivors are overwhelmingly discharged to institutional rehabilitation [39,44], determining if racial differences in rehabilitation intensity and setting exist nationally and the extent to which they lead to racial differences in post-stroke disability is needed. Importantly, access to postacute care is readily modifiable by both clinical policy (guidelines or practice improvement) and public policy (optimizing insurance coverage for rehabilitation and disability accommodations) [45].

\section{Post-stroke: Community Living}

Finally, racial differences in post-stroke disability may be associated with community living factors. Disability accommodations refer to the changes a stroke survivor makes to their life to overcome decreased functional capacity and to continue to perform activities. These range from performing activities more slowly to using assistive devices, such as canes/walkers, to changes in the home environment (grab bars, hand rails, and ramps), and to requiring personal assistance [46, 47]. These accommodations enhance the ability of stroke survivors to perform activities and may reduce the need for help with activities $[48,49]$. However, in a nationally representative sample of stroke survivors, there were no racial differences in disability accommodations among elderly stroke survivors, suggesting that these do not play a role in racial differences in post-stroke disability [50].
Additional early recovery and community living factors may also contribute to racial differences. Limited data suggest that medical factors in the post-stroke period such as recurrent stroke $[22,51,52]$ and hospital readmission for post-stroke complications [53] may be associated with racial differences in post-stroke disability, but these have not been studied directly. In addition, social/psychological factors such as social networks [54, 55], self-efficacy [56], and resilience [56] may have important roles in poststroke disability, but have been inadequately studied. Similarly, neighborhood cohesion is associated with reduced post-stroke mortality particularly among white stroke survivors, but little is known about racial differences [57]. In addition, little is known about the environment where stroke survivors reside including food store availability, safety, toxin exposure, and their possible association to racial differences in post-stroke disability.

\section{Conclusion}

Further work is needed to explore factors contributing to racial difference in post-stroke disability, with particular attention to the early recovery period. Longitudinal studies are needed to understand that both factors lead to post-stroke disability, and when during the post-stroke period, they may contribute. Cohort studies with measures of pre-stroke disability and repeated measures of disability over time such as REasons for Geographic And Racial Differences in Stroke (REGARDS), Cardiovascular Health Study (CHS), and NHATS are all wellpositioned to address many of these questions. In addition to race differences, recent studies have identified increased post-stroke disability among Hispanics who also have a higher stroke incidence compared to NHWs for which further study is needed $[15,58,59]$. In conclusion, evaluation of modifiable factors that are associated with racial differences in post-stroke disability including medical, rehabilitation, social/psychological, environmental, and improved study designs is needed to address this important area.

\section{Compliance with Ethics Guidelines}

Conflict of Interest LE Skolarus and JR Burke both declare no conflicts of interest.

Human and Animal Rights and Informed Consent This article does not contain any studies with human or animal subjects performed by any of the authors. 


\section{References}

Papers of particular interest, published recently, have been highlighted as:

- Of importance

•- Of major importance

1. Feigin VL, Lawes CMM, Bennett DA, Anderson CS. Stroke epidemiology: a review of population-based studies of incidence, prevalence, and case-fatality in the late 20th century. Lancet Neurol. 2003;2(1):43-53.

2. Go AS, Mozaffarian D, Roger VL, et al. Heart disease and stroke statistics-2014 update: a report from the American Heart Association. Circulation. 2014;129(3):e28.

3. Ovbiagele B, Goldstein LB, Higashida RT, et al. Forecasting the future of stroke in the United States: a policy statement from the American Heart Association and American Stroke Association. Stroke. 2013;44(8):2361-75.

4. United States Census Bureau National Population Projections. $\mathrm{http} / / / w w w . c e n s u s . g o v /$ population/projections/data/national/2012. html. Accessed September 10, 2013.

5. Wilkinson PR, Wolfe CDA, Warburton FG, et al. A long-term follow-up of stroke patients. Stroke. 1997;28(3):507-12.

6. Kelly-Hayes M, Beiser A, Kase CS, Scaramucci A, D'Agostino $\mathrm{RB}$, Wolf PA. The influence of gender and age on disability following ischemic stroke: the Framingham study. J Stroke Cerebrovasc Dis. 2003;12(3):119-26.

7.• Howard VJ, Kleindorfer DO, Judd SE, et al. Disparities in stroke incidence contributing to disparities in stroke mortality. Ann Neurol. 2011;69(4):619-27. Using data from the Reasons for Geographic And Racial Differences in Stroke (REGARDS) study, a longitudinal population-based cohort study, this study demonstrates that African Americans have a greater incidence of stroke and higher stroke mortality than non-Hispanic whites.

8. Kleindorfer DO, Khoury J, Moomaw CJ, et al. Stroke incidence is decreasing in whites but not in blacks: a population-based estimate of temporal trends in stroke incidence from the Greater Cincinnati/ Northern Kentucky Stroke Study. Stroke. 2010;41(7):1326-31. This study from the Greater Cincinnati/Northern Kentucky Stroke Study found increasing racial disparity for stroke incidence as non-Hispanic Whites had a decrease in stroke incidence was not observed in African Americans.

9. Kissela B, Schneider A, Kleindorfer D, et al. Stroke in a biracial population: the excess burden of stroke among blacks. Stroke. 2004;35(2):426-31.

10. Kleindorfer D, Broderick J, Khoury J, et al. The unchanging incidence and case-fatality of stroke in the 1990s: a population-based study. Stroke. 2006;37(10):2473-8.

11. Prevalence of stroke-United States, 2006-2010. JAMA. 2012;308(3):228-230.

12. Roth DL, Haley WE, Clay OJ, et al. Race and gender differences in 1 -year outcomes for community-dwelling stroke survivors with family caregivers. Stroke. 2011;42(3):626-31.

13. Ottenbacher KJ, Campbell J, Kuo Y-F, Deutsch A, Ostir GV, Granger CV. Racial and ethnic differences in postacute rehabilitation outcomes after stroke in the United States. Stroke. 2008;39(5): 1514-9.

14. Kissela B, Lindsell CJ, Kleindorfer D, et al. Clinical prediction of functional outcome after ischemic stroke: the surprising importance of periventricular white matter disease and race. Stroke. 2009;40(2): 530-6.

15. Dhamoon MS, Moon YP, Paik MC, et al. Long-term functional recovery after first ischemic stroke: the Northern Manhattan Study. Stroke. 2009;40(8):2805-11.

16. Burke JF, Freedman VA, Lisabeth LD, Brown DL, Haggins A, Skolarus LE. Racial differences in disability after stroke results from a nationwide study. Neurology. 2014;83(5):390-7. This paper identified national racial differences in post-stroke disability among the elderly.

17. Kissela B, Lindsell CJ, Kleindorfer D, et al. Clinical prediction of functional outcome after ischemic stroke the surprising importance of periventricular white matter disease and race. Stroke. 2009;40(2): $530-6$.

18. Capistrant BD, Mejia NI, Liu SY, Wang Q, Glymour MM. The disability burden associated with stroke emerges before stroke onset and differentially affects Blacks: results from the Health and Retirement Study Cohort. The Journals of Gerontology Series A: Biological Sciences and Medical Sciences. 2014:glt191.

19. Burke JF, Skolarus LE, Freedman VA. Abstract T P131: racial disparities in post-stroke activity limitations are not due to prestroke activity limitation differences. Stroke. 2015;46 Suppl 1: ATP131

20. White H, Boden-Albala B, Wang C, et al. Ischemic stroke subtype incidence among whites, blacks, and Hispanics: the Northern Manhattan study. Circulation. 2005;111(10):1327-31.

21. Lin H-J, Wolf PA, Kelly-Hayes M, et al. Stroke severity in atrial fibrillation: the Framingham study. Stroke. 1996;27(10):1760-4.

22. Luengo-Fernandez R, Paul NLM, Gray AM, et al. Populationbased study of disability and institutionalization after transient ischemic attack and stroke: 10-year results of the Oxford Vascular Study. Stroke. 2013;44(10):2854-61.

23. Hartmann A, Rundek T, Mast H, et al. Mortality and causes of death after first ischemic stroke The Northern Manhattan Stroke Study. Neurology. 2001;57(11):2000-5.

24. Kleindorfer D, Lindsell C, Alwell KA, et al. Patients living in impoverished areas have more severe ischemic strokes. Stroke. 2012;43(8):2055-9.

25. Reeves M, Khoury J, Alwell K, et al. Distribution of National Institutes of Health Stroke Scale in the Cincinnati/Northern Kentucky Stroke Study. Stroke. 2013;44(1):3211-3.

26. Qian F, Fonarow GC, Smith EE, et al. Racial and ethnic differences in outcomes in older patients with acute ischemic stroke. Circ Cardiovasc Qual Outcomes. 2013;6(3):284-92.

27. Jones MR, Horner RD, Edwards LJ, et al. Racial variation in initial stroke severity. Stroke. 2000;31(3):563-7.

28. Schwamm LH, Reeves MJ, Pan W, et al. Race/ethnicity, quality of care, and outcomes in ischemic stroke. Circulation. 2010;121(13): 1492-501.

29. Meyer S, Verheyden G, Brinkmann N, et al. Functional and motor outcome 5 years after stroke is equivalent to outcome at 2 months: follow-up of the collaborative evaluation of rehabilitation in stroke across Europe. Stroke May. 2015;7:2015.

30. Granger CV, Markello SJ, Graham JE, Deutsch A, Ottenbacher KJ The uniform data system for medical rehabilitation: report of patients with stroke discharged from comprehensive medical programs in 2000-2007. Am J Phys Med Rehabil. 2009;88(12):96172 .

31. Duncan PW, Zorowitz R, Bates B, et al. Management of adult stroke rehabilitation care: a clinical practice guideline. Stroke. 2005;36(9):e100-143. 
32. Langhorne P, Duncan P. Does the organization of postacute stroke care really matter? Stroke. 2001;32(1):268-74.

33. Medicare Payment Advisory Commission. Report to the congress: medicare payment policy http://www.medpac.gov/documents/ Mar13 entirereport.pdf. Accessed October 16, 2013.

34. Coverage of Inpatient Rehabilitation Services. 2010; http://www. cms.gov/MLNMattersArticles/downloads/MM6699.pdf. Accessed June 14, 2011.

35. Jette DU, Warren RL, Wirtalla C. The relation between therapy intensity and outcomes of rehabilitation in skilled nursing facilities. Arch Phys Med Rehabil. 2005;86(3):373-9.

36. Ronning OM, Guldvog B. Outcome of subacute stroke rehabilitation: a randomized controlled trial. Stroke. 1998;29(4):779-84.

37. Lo AC, Guarino PD, Richards LG, et al. Robot-assisted therapy for long-term upper-limb impairment after stroke. N Engl J Med. 2010;362(19):1772-83.

38. Legg L. Rehabilitation therapy services for stroke patients living at home: systematic review of randomised trials. Lancet. 2004;363(9406):352-6.

39. Buntin MB, Colla CH, Deb P, Sood N, Escarce JJ. Medicare spending and outcomes after postacute care for stroke and hip fracture. Med Care. 2010;48(9):776-84.

40. Kramer AM. Outcomes and costs after hip fracture and stroke: a comparison of rehabilitation settings. JAMA (Chicago, Ill). 1997;277(5):396-404.

41. Deutsch A, Granger CV, Heinemann AW, et al. Poststroke rehabilitation: outcomes and reimbursement of inpatient rehabilitation facilities and subacute rehabilitation programs. Stroke. 2006;37(6): 1477-82.

42. Kane RL, Chen Q, Blewett LA, Sangl J. Do rehabilitative nursing homes improve the outcomes of care? J Am Geriatr Soc. 1996;44(5):545-54.

43. Freburger JK, Holmes GM, Ku L-JE, Cutchin MP, Heatwole-Shank $\mathrm{K}$, Edwards LJ. Disparities in postacute rehabilitation care for stroke: an analysis of the state inpatient databases. Arch Phys Med Rehabil. 2011;92(8):1220-9.

44. Kramer A, Holthaus D, Goodrish G, Epstein A. A study of stroke post-acute care costs and outcomes: final report. Executive summary. Washington (DC): US Department of Health and Human Services; 2006.

45. Matchar DB. Health policy in stroke: translating what we know into what we do. Stroke. 2003;34(2):370-1.

46. Freedman VA, Agree EM, Cornman JC, Spillman BC, Kasper JD. Reliability and validity of self-care and mobility accommodations measures in the national health and aging trends study. Gerontologist. 2013:gnt104.

47. Freedman VA. Adopting the ICF language for studying late-life disability: a field of dreams? J Gerontol A Biol Sci Med Sci. 2009;64A(11):1172-4.

48. Agree EM, Freedman VA. Incorporating assistive devices into community-based long-term care: an analysis of the potential for substitution and supplementation. J Aging Health. 2000;12(3):42650 .

49. Hoenig H, Taylor Jr DH, Sloan FA. Does assistive technology substitute for personal assistance among the disabled elderly? Am J Public Health. 2003;93(2):330-7.

50. Skolarus LE, Burke JF, Freedman VA. The role of accommodations in poststroke disability management. J Gerontol B Psychol Sci Soc Sci. 2014;69 Suppl 1:S26-34.

51. Sheinart K, Tuhrim S, Horowitz D, Weinberger J, Goldman M, Godbold J. Stroke recurrence is more frequent in blacks and Hispanics. Neuroepidemiology. 1998;17(4):188-98.

52. Hardie K, Hankey GJ, Jamrozik K, Broadhurst RJ, Anderson C. Ten-year risk of first recurrent stroke and disability after first-ever stroke in the Perth community stroke study. Stroke. 2004;35(3): 731-5.

53. Lichtman JH, Leifheit-Limson EC, Jones SB, et al. Predictors of hospital readmission after stroke: a systematic review. Stroke. 2010;41(11):2525-33.

54. Colantonio A, Kasl SV, Ostfeld AM, Berkman LF. Psychosocial predictors of stroke outcomes in an elderly population. J Gerontol. 1993;48(5):S261-8.

55. Boden-Albala B, Litwak E, Elkind M, Rundek T, Sacco R. Social isolation and outcomes post stroke. Neurology. 2005;64(11):188892.

56. Self-efficacy and self-management after stroke: a systematic review. Disabil Rehabil. 2011;33(10):797-810.

57. Clark CJ, Guo H, Lunos S, et al. Neighborhood cohesion is associated with reduced risk of stroke mortality. Stroke. 2011;42(5): 1212-7.

58. Lisabeth LD, Sánchez BN, Baek J, et al. Neurological, functional, and cognitive stroke outcomes in Mexican Americans. Stroke. 2014;45(4):1096-101.

59. Morgenstern LB, Smith MA, Sánchez BN, et al. Persistent ischemic stroke disparities despite declining incidence in Mexican Americans. Ann Neurol. 2013;74(6):778-85. 